\title{
MESTRES EM CANTARIA: TECNOLOGIA E PRÁTICA
}

\author{
Frederico Faria Neves Almeida \\ Engenheiro Civil, Técnico III - IPHAN - PE \\ fredalmeida@iphan.gov.br
}

Resumo: A mesa redonda intitulada "MESTRES EM CANTARIA: tecnologia e prática" pretendeu trazer para o 1o Simpósio Brasileiro de Caracterização e Conservação da Pedra uma discussão sobre a situação atual da profissão de Mestres Canteiros, a partir dos recentes trabalhos de conservação e restauração de cantaria realizados no Brasil. Promoveu um debate sobre a evolução das técnicas utilizadas, focando também os temas mão de obra, métodos, materiais e produtos atualmente disponíveis no mercado brasileiro. Foram convidados para essa mesa redonda professores e mestres canteiros participantes do curso de formação profissional no Centro de Conservação $e$ Restauro de Veneza - Itália, em 2001, através do Programa do Ministério da Cultura - Monumenta/IPHAN. Os centros de pesquisa tecnológica existentes em nosso país são raros e pouco requisitados pelos técnicos envolvidos em trabalhos de conservação/restauração de cantarias. O distanciamento desses técnicos em relação aos centros de tecnologia é unanimemente reconhecido por eles. A situação dos profissionais de conservação/restauração em cantaria no Brasil não é fácil, carece de capacitação e de perenidade de obras de restauração e conservação. Buscou-se, nesse Simpósio, fazer uma avaliação sintética do mercado de trabalho e do desenvolvimento tecnológico a partir do Plano de Treinamento e Formação de Mão de Obra, promovido pelo MinC através do Programa Monumenta/IPHAN.

Palavras Chave: cantaria, mestres, tecnologia

Abstract: MASTERS IN MASONRY: TECNOLOGY AND PRACTICE. This article aims to deal the issue of conservation policies in Brazil, focused on built cultural heritage, specifically regarding to stone materials, The round table entitled "MASTERS IN MASONRY: technology and practice" intended to bring to the 1st Brazilian Symposium on Stone Characterization and Conservation a discussion on the current situation of the profession of Masonry workers, starting from the recent works of conservation and restoration of masonry done in Brazil. It intended to bring up a debate on the evolution of the techniques used in this art, also focusing on the following subjects: labor, methods, materials and products currently available in the Brazilian market. Teachers and masons who took part in the professional formation course in the Restoration Center of Venice - Italy, in 2001, through the Ministry of Culture - Monumenta / IPHAN Program were invited to this round table. The technological research centers in our country are rarely requested by technicians involved in conservation works. The distancing of these technicians from the technology centers is unanimously recognized by them. The situation of conservation / restoration professionals in masonry in Brazil is not easy, it needs both training and the permanence of restoration and conservation works. This Symposium intended to make a brief evaluation of both the labor market and the technological development based on the MinC Monumenta / IPHAN Program for Training and Manual Labour Formation Plan.

Keywords: masonry, masons, technology

\section{INTRODUÇÃO}

A qualidade das obras de conservação e restauração de monumentos históricos depende diretamente do desenvolvimento tecnológico e consequentemente das técnicas de conservação/restauração. Está, também, diretamente ligada ao mercado de trabalho profissional e à existência continuada de obras de conservação e restauração de bens imóveis de valor cultural. Inclui-se, nesse contexto, a evolução tecnológica dos serviços de cantaria, suas práticas e o desenvolvimento de técnicas e materiais. Os centros de pesquisa e de capacitação profissional garantiriam, em tese, a evolução de técnicas, materiais, ferramentas e produtos utilizados nos serviços de cantaria.

Embora, no Brasil, existam inúmeros centros de pesquisa capazes de caracterizar os tipos de rochas utilizadas nos monumentos históricos brasileiros, pouco se verifica a solicitação desse serviço em projetos ou obras de conservação e restauração de edifícios históricos.

Os planos de treinamento e formação profissional promovidos no passado podem estar comprometidos pelas dificuldades de captação de

doi: 10.18285/geonomos.v24i2.841 recursos financeiros e também pela crise em que o país se encontra. $\mathrm{O}$ distanciamento do conhecimento tecnológico dos profissionais envolvidos na área de conservação/restauração de edifícios históricos pode estar relacionado com a ausência de disciplinas voltadas à preservação do patrimônio arquitetônico. A multidisciplinaridade desse campo profissional permite pesquisas em diversas áreas de atuação - arquitetura, engenharia, geologia, química, física, biologia, etc.

A crise atualmente existente no Brasil tem comprometido várias obras em andamento no país. Apesar de o PAC das Cidades Históricas ter sofrido cortes e supressões de recursos financeiros, ainda se mantém como o maior Programa de Recuperação de Centros Históricos já implantado pelo Governo Federal.

Os aspectos positivos e negativos relacionados ao tema abordado na mesa redonda "Mestres em Cantaria: tecnologia e prática" foram discutidos a partir do debate ocorrido no 10 Simpósio Brasileiro de Caracterização e Conservação da Pedra, cujos convidados foram os professores Dr. Mario Mendonça de Oliveira, Professor da UFBA e Coordenador do Núcleo de Tecnologia da Preservação e da Restauração em Savador/BA; Dr. Ricardo de Cristofaro, Doutor em Artes Visuais pela Universidade Federal do Rio Grande do Sul, artista 
plástico e professor do Instituto de Artes e Design da UFJF; e os mestres canteiros Hamilton Martins, de Olinda/PE; Rinaldo Urzedo, de Minas Gerais e Everaldo de Matos Abreu, da Bahia - mestres participantes do curso de formação profissional do Centro de Conservação e Restauro de Veneza - Itália, em 2001, através do Programa do Ministério da Cultura - Monumenta/IPHAN.

O professor Mario Mendonça de Oliveira iniciou o debate primeiramente fazendo uma homenagem aos mestres canteiros, destacando a importância destes e dos demais mestres artífices, que usam as mãos como ferramenta e "não fazem um trabalho menor". Citou os arquitetos Pierre de Montreuil ${ }^{1} \mathrm{e}$ Violet le Duc ${ }^{2}$ como exímios intelectuais históricos, amantes do trabalho em cantaria. Falou sobre o distanciamento da academia em relação aos trabalhos práticos, valorizando os trabalhos dos mestres. Referiu-se também à necessidade de se preservar o "ofício do canteiro", afirmando que se trata de patrimônio cultural. Apontou a obra do Mercado Modelo de Salvador como exemplo de integração entre os mestres artífices e os mestres professores. Em função dessa experiência surgiu, dentro da Universidade Federal da Bahia, o curso de formação de mão de obra que, posteriormente, originou a Oficina Escola de Salvador.

\section{EVOLUÇÃO DE TÉCNICAS DE CONSERVAÇÃO E RESTAURAÇÃO DE CANTARIAS}

Os métodos de limpeza de cantaria, em meu entendimento, não têm evoluído. Testes e ensaios laboratoriais prévios são pouco realizados. O método com jato de água pressurizada é o mais utilizado, no entanto não há qualquer controle de volume e pressão de água sobre a cantaria. A contaminação da cantaria por sais solúveis poderá ser agravada através da maior penetração de água na superfície da pedra e, consequentemente, de sais solúveis. Poucos testes e ensaios são solicitados pelos profissionais que trabalham com a conservação da pedra.

Vários testes e ensaios laboratoriais e de campo poderiam ajudar na avaliação dos métodos de limpeza de cantaria a serem utilizados: porosidade, densidade, cor, brilho, composição química, etc. certamente podem definir os melhores instrumentos a serem utilizados na conservação de materiais pétreos. O método de limpeza por tentativas progressivas ${ }^{3}$ necessita de ensaios $\mathrm{e}$

\footnotetext{
Arquiteto mestre do gótico radiante e chefe do reinado de St. Louis. Em Paris, construiu o refeitório e a capela da abadia de Saint-Germain-des-Près. A partir de 1265 dirigiu as obras da Catedral de Notre-Dame. Autor da Sainte-Chapelle e do refeitório de Saint-Martin-des-Champs (Biblioteca de Artes e Ofícios)

Eugène Emannuel Viollet-le-Duc foi um arquiteto francês ligado à arquitetura revivalista do século XIX e um dos primeiros teóricos da preservação do patrimônio histórico. Pode ser considerado como um precursor teórico da arquitetura moderna 3 Método em que se aumenta gradativamente 0 grau de aressividade da metodologia tração de produtos químicos e a utilização de ferramentas mais ou menos abrasivas.
}

testes prévios que determinarão a melhor forma de limpeza com menor agressividade sobre a cantaria. Não percebemos a realização desses testes na maioria dos trabalhos realizados, nem tampouco nos projetos apresentados (Iphan-PE, 2014). A falta de conhecimento, os custos e a dificuldade de acesso aos centros de pesquisas são causas possíveis que afetam a qualidade e a eficiência dos trabalhos. Verificou-se, no Simpósio, que existem vários trabalhos de caracterização e de pesquisa, mas fortemente desassociados dos trabalhos de conservação de cantarias.

Como era esperado, percebeu-se no debate entre mestres e professores que o uso de próteses de pedra é unanimemente defendido pelos mestres artífices, pois o mercado de trabalho de cantaria está diretamente ligado ao uso de próteses no processo de restauração de monumentos históricos em pedra.

Nos trabalhos de Cantaria, a mão de obra especializada é fundamental para garantir a boa qualidade da restauração e conservação de cantarias. Só o profissional especializado (canteiro) tem condições de realizar próteses esculpidas para aplicação em monumentos de pedra e cal.

Um dos desafios a se enfrentar é o processo de extração de rochas nas jazidas. A extração com equipamentos de corte com discos diamantados vem sendo aprimorada no Brasil e permite a captação de pedra de grandes dimensões. Muitas vezes as jazidas no Brasil não são devidamente regulamentadas e as licenças dos órgãos ambientais e de mineração são obrigatórias, devendo ser mantidos os registros das jazidas atualizados sob pena de paralisação da extração.

O tipo de pedra, a cor e a textura devem ser muito bem escolhidos, pois as variações das características físicas da rocha devem estar bem assemelhadas à cantaria que se pretende restaurar.

Extraída a pedra a ser utilizada na obra de restauração, outro problema a ser enfrentado é o transporte do bloco extraído, exigindo-se o auxílio de munks e guindastes para o devido transporte.

As próteses são normalmente utilizadas para preencher grandes lacunas ou enxertos de cantaria. Esculpem-se as próteses e estas são implantadas para complementação das cantarias, recuperandose modenaturas ou esculturas de pedra.

O uso de argamassas na restauração de cantarias é uma tendência que vem sendo ampliada nas obras de restauração e conservação de monumentos históricos, pois, além de mais barato, possibilita seu manejo por outros profissionais. Exigem-se cuidados especiais para que a intervenção se restrinja apenas às lacunas da superfície da cantaria. 
Em grandes lacunas, recomenda-se a aplicação de próteses de pedra ou estruturação de modenaturas com aço inox e preenchimento com argamassas entonadas de acabamento superficial adequado.

Testes a serem realizados para a definição de traços de argamassas ainda merecem ser aprimorados. A resistência mecânica e o tempo de cura das argamassas de cal normalmente são baixos, devendo estas, em certos casos, ser aditivadas com pozolânicos ou mesmo com cimentos. Além disso, a compatibilidade dessas argamassas com o material pétreo deve ser garantida através de testes e ensaios laboratoriais, o que normamente não é realizado.

$\mathrm{Na}$ mesa redonda não houve espaço para debater o uso de argamassas em restauração de cantarias. Apenas citou-se a possibilidade de utilização de argamassas nos preenchimentos de pequenas lacunas visando à conservação/restauração da cantaria.

Os trabalhos realizados no Nordeste, em geral, têm evitado restauração com a utilização de resinas sintéticas. As resinas acrílicas, poliéster ou epóxicas têm demonstrado forte incompatibilidade com os tipos de rochas usadas na cantaria dos nossos monumentos históricos. Em cantarias expostas às intempéries, as resinas não têm sido eficazes no processo de restauração. Mesmo com filtros UV e IV, as cores previamente testadas modificam-se de modo a tornarem-se "manchas escuras" na cantaria.

A utilização de proteção superficial através de resinas acriloides ou silicatos merece atenção redobrada. Além de causar alteração de texturas ou brilhos indesejáveis na superfície pétrea, pode provocar a criação de "película" impermeável, fator determinante para evitar sua utilização sem testes ou comprovações científicas adequadas.

As resinas epóxicas, acrílicas ou poliéster podem ser utilizadas como colagem ou fixação de prótese de pedra, mas não são recomendadas nos acabamentos superficiais. Nas cantarias históricas realizadas com os arenitos oriundos dos arrecifes do Recife, a restauração com resinas misturadas com pó de pedra têm dado bom resultado, após o apicoamento da superfície.

O uso de resinas foi, unanimemente, considerado apenas em condições bastante especiais e de forma excepcional. A reversibilidade foi defendida por todos.

Dependendo do tipo de pedra a ser trabalhada, as ferramentas exigem maior ou menor resistência à abrasão ou ao corte. Muitos dos canteiros são especializados no fabrico e na afiação de ferramentas resistentes. Os granitos exigem ferramentas mais resistentes e com afiação mais afinada. Já os calcários e a pedra sabão são riscados e entalhados com facilidade. As ferramentas elétricas, abrasivas e/ou de corte são muito úteis, mas exigem capacitação específica e o uso de $\mathrm{EPI}^{4}{ }^{4}$ a fim de evitar acidentes graves.

Para os mestres canteiros, há, sim, uma evolução, mas verifica-se, pelas palavras dos mestres Everaldo, Hamilton e Rinaldo, que essa evolução é muito mais das técnicas práticas do que das tecnológicas. As ferramentas são praticamente as mesmas, mas, dependendo do tipo de rocha (dureza), devem ser fabricadas ou afiadas pelo próprio canteiro. Há uma diferença substancial entre as ferramentas para uso em diversos tipos de rochas.

Para o professor Ricardo Cristofaro, uma das maiores dificuldades é encontrar as ferramentas adequadas para cada tipo de trabalho. No Brasil, quase todas as ferramentas são fabricadas pelos mestres ou são importadas.

Os mestres canteiros ratificam as dificuldades de se obterem as ferramentas adequadas e afirmam que cada profissional tem sua própria técnica de fabricação, uso e afiação de ferramentas conforme o tipo de rocha que está sendo trabalhada.

\section{RELAÇÃO DOS MESTRES CANTEIROS X CENTROS DE PESQUISA}

Tem-se verificado a ausência de ensaios laboratoriais e de campo nos trabalhos de restauração de cantaria. Constata-se, na maioria dos projetos aprovados, a especificação da necessidade de realização de testes e ensaios durante a realização da obra de restauração de cantarias. No entanto, verifica-se, na prática, que esses testes, quando realizados, são feitos de forma empírica, sem procedimento científico regulamentado ou mesmo sem acompanhamento tecnológico. Testes de resistência e de caracterização física (densidade, composição química, porosidade, dureza, cor, etc.) normalmente não são realizados. Muitas vezes, a exigência desses testes provoca protestos e recusas por parte dos executores das obras de restauração, alegando-se frequentemente a sua ausência nas especificações técnicas do projeto, além dos custos e do tempo que esses ensaios podem demandar. Poucos técnicos especializados em cantaria buscam apoio nos laboratórios científicos ou centros de pesquisa.

A falta de divulgação e de pesquisas realizadas pelos laboratórios especializados no Brasil pode ser um dos motivos do distanciamento dos técnicos em

\footnotetext{
${ }^{4}$ EPI - Equipamento de Proteção Individual.
} 
restauração de monumentos históricos de tais centros de pesquisa.

A grande diversidade de tipos de testes e ensaios e a falta de conhecimento na utilização dos resultados também podem motivar esse distanciamento tecnológico dos profissionais. Tal desconhecimento - da parte do profissional que elabora os projetos - sobre ensaios de caracterização de pedras como porosidade, densidade, dureza, composição mineralógica, etc., que poderiam ajudar na decisão das técnicas restaurativas a serem utilizadas impede que esses testes sejam solicitados, pois esses profissionais, em certos casos, não sabem compreender os resultados desses ensaios, ou mesmo como eles poderiam auxiliar na sua decisão.

Os cursos de nível superior no Brasil que têm interface com a área de conservação e restauração de monumentos históricos (arquitetura, engenharia, química, biologia, etc.) cada vez mais se distanciam da área tecnológica voltada para a preservação de bens imóveis de valor cultural. Os cursos de arquitetura, que formam o profissional habilitado a coordenar projetos e obras de conservação e restauração de edifícios históricos ${ }^{5}$, têm-se distanciado do objeto a ser preservado. Práticas e saberes desenvolvidos no passado estão sendo esquecidos aos poucos. Mestres e Profissionais em restauração de bens imóveis estão-se tornando cada vez mais raros e técnicas tradicionais não estão sendo repassadas para as gerações futuras. As disciplinas voltadas para o desenvolvimento tecnológico nas universidades não estimulam a realização de pesquisas científicas, testes ou ensaios laboratoriais. A procura de cursos profissionalizantes na área de conservação e restauro no Brasil tem sofrido baixa considerável. Cursos como os existentes em São Paulo, Salvador, Belo Horizonte e Recife vêm reduzindo o número de turmas e a busca por interessados é fator preponderante na manutenção desses cursos.

Para o mestre Hamilton Martins, o distanciamento científico se deve à falta de conhecimento tecnológico dos profissionais que trabalham em cantaria. O reflexo da fragilidade da educação escolar de 10 grau desses mestres dificulta o aprendizado o que, aliado ao desinteresse desses profissionais, compromete a qualidade dos serviços de cantaria. Ele, como atua como professor do $\mathrm{CECl}$ - Curso de Gestão de Obras de Restauro - e é

\footnotetext{
5 Resolução CAU/BR no 51/2013, Artigo 2ㅇ, Inciso IV - onde fica especificada como privativa dos arquitetos e urbanistas a coordenação de projeto e de execução de obras de intervenção no patrimônio histórico cultural e artístico, arquitetônico, urbanístico, paisagistico, monumentos, práticas de projeto e soluç̃os tecnológicas para reutilizaço, pasagistico, mon edificações, conjuntos e cidades:
}

servidor do Iphan, tem tido oportunidade de, em conjunto com professores, arquitetos, engenheiros, químicos e geólogos proporcionar um debate sobre problemas práticos de execução e restauração de cantarias.

Tanto para o Prof. Mario Mendonça quanto para - Prof. Antônio Gilberto, há uma completa desvinculação da universidade com relação às atividades práticas no campo da conservação e restauração de edifícios históricos. Muitas vezes o pesquisador não se dá conta de que aquela pesquisa tem uma aplicação prática.

O Prof. José Delgado entende que, se o objeto a ser preservado é o centro da questão, nós, técnicos, é que devemos colocar nossas ideias em prática e não o contrário, isto é, nossas ideias serem o centro para serem aplicadas no objeto a ser preservado.

Os cursos de arquitetura têm-se voltado para a realização de pesquisas na área de gestão do patrimônio. As disciplinas na área tecnológica têm sido pouco valorizadas e são consideradas matérias secundárias.

O papel da universidade é promover a pesquisa, os estudos em áreas específicas, com vistas ao desenvolvimento tecnológico (Vares, CIEE/SP, 2012). O mercado do ensino, a partir dos anos 90, tem-se voltado para números e estatísticas, mesmo que isso venha a diminuir a qualidade do ensino superior. $O$ ingresso nas universidades tem sido cada vez mais popularizado. O surgimento de novas instituições de ensino públicas e privadas e a consequente ampliação do número de vagas têm tornado os cursos de nível superior mais acessíveis. Isso tem causado o barateamento dos preços das mensalidades, o que, somado aos baixos salários dos professores, tem interferido na qualidade do ensino e na redução de linhas de pesquisa e capacitação profissional.

A maioria dos cursos existentes no Brasil está relacionada com a gestão do patrimônio cultural; poucos estão voltados para o desenvolvimento tecnológico de técnicas, materiais e produtos.

Pela multidisciplinaridade do campo de conservação e restauração de monumentos e sítios históricos, a universidade deveria promover mais fortemente a integração dos diversos cursos de graduação, aproximando-os de linhas de pesquisa específicas, voltadas para a preservação do patrimônio cultural.

Dr. Joaquim Luís Galego Lopes, da Universidade de Évora, apontou que, em Portugal, também há 
uma falta de continuidade de demanda de trabalhos de cantaria, o que, consequentemente, põe em risco o ofício dos mestres canteiros, mas afirmou que essa demanda depende da abertura entre o pesquisador e o prático, ou seja, depende de nós.

O arquiteto aposentado do Iphan Cyro Corrêa Lyra registrou que, no Rio de Janeiro, há um curso de mestres mantido pela Fundação Calouste Gulbenkian, nas áreas de carpintaria, estuque, serralharia, etc., que foi montado a partir da experiência do Programa de Capacitação em Conservação e Restauração de Monumentos Históricos realizado pelo Monumenta/IPHAN, mas, infelizmente, não se previu um curso de conservação de cantarias.

\section{MERCADO DE TRABALHO NO CAMPO DA CONSERVAÇÃO E RESTAURAÇÃO DE MONUMENTOS HISTÓRICOS}

A recessão que castiga o mercado de trabalho e trava investimentos tem tirado oportunidades e desempregado uma mão de obra considerada importante por especialistas para o setor produtivo brasileiro aprimorar processos, incorporar novas tecnologias e aumentar a visibilidade profissional.

A perda das práticas no trato com o material pétreo tem sido sentida desde a década de 30 . Constatou-se a necessidade da cantaria como técnica de restauro visto que grande parte do patrimônio edificado no Brasil possuía algum tipo de rocha lapidada ${ }^{6}$ (UFOP, 2004)

Visando à multiplicação de mão de obra qualificada em conservação e restauração de monumentos históricos, o Ministério da Cultura, através do Programa Monumenta/IPHAN, promoveu, em 2001, um programa de formação profissional em seis ofícios tradicionais: Canteiro, Carpinteiro, Estucador, Ferreiro, Pedreiro e Pintor. 34 mestres artífices de vários estados brasileiros foram capacitados em restauração de monumentos históricos no Centro de Conservação e Restauro de Veneza - Itália (MINC, Relatório de Gestão, 2001). Seis (6) desses trinta e quatro (34) mestres artífices são mestres canteiros, dos quais três (3) foram convidados a participar do 1ㅇ Simpósio de Caracterização e Conservação da Pedra. Pretendeuse sintetizar a situação do mercado de trabalho nos estados onde esses profissionais atuam, verificandose a realidade do campo da conservação e produção de cantarias. Um dos fatores multiplicadores de mão de obra foi a capacitação desses mestres para a

Anais do 20 Congresso Brasileiro de Extensão Universitária. Belo Horizonte - 12 a 15 de setembro de 2004 reprodução desse conhecimento adquirido para as gerações futuras. Em Pernambuco, o mestre Hamilton Martins e outros dois mestres capacitados no programa de formação profissional do Monumenta têm repassado o conhecimento adquirido para novos profissionais e estão formando, em Pernambuco, um grupo de canteiros e restauradores, difundindo o trabalho tanto em nível local como em outros estados. Já realizaram serviços de restauração de monumentos históricos no Maranhão, na Bahia e em Pernambuco.

Cyro Corrêa Lyra, que participou da seleção dos mestres artífices no programa Monumenta/IPHAN e acompanhou o desempenho deles, lamentou que, devido ao Programa, o único ofício que não resultou na criação de cursos de mestres no Brasil foi o ofício de Canteiro.

O mestre Everaldo tem-se especializado em manufatura de pedras duras (granitos), o que exige um desenvolvimento prático de fabrico e de afiação de ferramentas específicas para cantaria de pedras graníticas.

O mercado de trabalho de conservação e restauração de monumentos históricos é muito dependente dos recursos oriundos dos poderes públicos federal, estadual e municipal, ou daqueles que são patrocinados pelas leis de incentivo à cultura dessas três esferas. Há uma forte retração da sociedade quanto a investir nos bens imóveis de valor cultural de propriedade privada, pois sempre se espera que o poder público venha a fazer o papel de conservar os bens desse tipo de propriedade. Isso afeta diretamente o mercado de trabalho e o desenvolvimento tecnológico das práticas e técnicas aplicadas em conservação de cantarias.

Como a mão de obra de cantaria é cada dia mais rara, o custo do trabalho dos profissionais dessa área tem-se tornando mais elevado em relação ao de outros profissionais da construção civil. Os mestres artífices têm-se tornado escassos e as obras de restauração também são raras, portanto a relação demanda e oferta nesses dias de crise tem tendido a se equilibrar.

Dos três mestres canteiros presentes no Simpósio, dois são servidores públicos e todos afirmaram que não vivem exclusivamente dos trabalho de cantaria. O mercado de esculturas de pedra vem servindo de caminho paliativo para os mestres artífices em cantaria. Na ausência de trabalhos de conservação e restauração de monumentos, essas esculturas são executadas e 
vendidas para atender um mercado também carente de fortalecimento.

O Prof. Ricardo Cristofaro defende o registro das práticas escultóricas realizando uma catalogação das técnicas utilizadas para promover uma renovação e difusão dessas práticas e o repasse do conhecimento prático. Ele vê isso como uma saída para a preservação do ofício do canteiro.

O mestre Rinaldo afirma que, se houver demanda, a mão de obra aparecerá, ou seja, a preservação do ofício de canteiro está diretamente relacionada com o mercado de trabalho, e a existência de obras de conservação e restauração do patrimônio edificado é, em tese, um forte agente para a manutenção desse mercado.

\section{CONSIDERAÇÕES FINAIS}

Pelos temas abordados na mesa redonda proposta, verifica-se a necessidade de ainda se realizarem muitas ações para que se possa garantir um desenvolvimento tecnológico sustentável para as ações de conservação de monumentos históricos e de cantarias. Políticas de patrimônio e incentivos fiscais deveriam ser implantadas para estimular a realização de serviços de conservação e restauração de bens protegidos. As universidades e os centros de pesquisa poderiam ampliar as linhas de pesquisa voltadas para o desenvolvimento tecnológico das práticas de restauro. A difusão dos tipos de ensaios e de laboratórios e o conhecimento profissional com vistas à utilização dos resultados para as práticas de restauração devem ser repassados aos técnicos envolvidos em obras de conservação e restauração.

O papel da universidade no campo da conservação e restauração de cantarias é estimular a integração interdisciplinar e a criação de linhas de pesquisas científicas voltadas para o desenvolvimento tecnológico e a difusão do conhecimento entre o corpo discente e o docente.

O PAC das Cidades Históricas - PAC- $\mathrm{CH}^{7}$, que tem a finalidade de fortalecer o campo de preservação, restauração e conservação de monumentos e conjuntos históricos em 44 cidades brasileiras, tem incentivado o mercado de obras de restauração. Uma das preocupações do Programa é estimular a formação de mão de obra especializada de modo a suprir a demanda planejada. A atual crise governamental e a falta de capacidade operacional das entidades executoras do Programa vêm

${ }^{7}$ O Programa de Aceleração do Crescimento (PAC), iniciado em 2007, é uma iniciativa do governo federal. Em 2013, o Ministério do Planejamento autorizou a criação de uma linha destinada exclusivamente aos sítios históricos urbanos protegidos pelo IPHAN, linha destinada exclusivamente aos sítios histo
dando origem ao PAC das Cidades Históricas. reduzindo essa demanda e, consequentemente, ocorre uma diminuição do crescimento esperado. Esperamos que a situação de crise financeira que o país atravessa se finde, e que o $\mathrm{PAC}-\mathrm{CH}$ retome o ritmo de execução de obras planejado e aqueça o mercado de trabalho de cantarias.

Do resultado da mesa redonda podemos registrar as seguintes abordagens e sugestões:

- Defesa quase unânime da proposta do registro do livro dos saberes e modos de fazer do "oficio de canteiro" no Brasil, catalogando as técnicas escultóricas, o preparo da pedra, as jazidas, as ferramentas e as técnicas de apontamento dessas ferramentas, pois o ofício de canteiro é cada vez mais raro no Brasil e merece ser registrado como patrimônio cultural.

- Os órgãos de preservação devem traçar políticas de valorização de trabalho de mestres artífices.

- Necessidade de integração dos trabalhos práticos com a universidade.

- Necessidade de ações de incentivo aos artífices para se organizarem em "empresa".

- Implementação de uma política de valorização do trabalho de canteiro, capitaneada pelos órgãos de preservação do patrimônio cultural.

- Necessidade de política de conservação e manutenção dos trabalhos de restauração executados.

- Necessidade de se promover uma maior exigência nas licitações, visando à melhoria da qualidade de serviços especializados e, consequentemente, à contratação de profissionais qualificados a realizar esses trabalhos.

- Necessidade de melhoria dos editais de licitação, evitando licitações pelo menor preço, valorizando editais de técnica e preço para obras de conservação e restauração de monumentos históricos.

- Necessidade de criação de um centro de pesquisa voltado para a conservação e restauração de cantarias, apontando o Museu de Congonhas como um possível local para sua instalação. 


\section{REFERÊNCIAS BIBLIOGRÁFICAS}

ALMEIDA, Frederico F. N. Manual de Conservação de Cantarias, Rio de Janeiro: Iphan, 2002.

FUNDACENTRO, MTB, EPI - Equipamentos de Proteção Individual: São Paulo, MT, 2013.

IPHAN, Ministério da Cultura. PAC das Cidades Históricas: Brasília: Iphan, 2016.

PESTANA, Til. Sobre O Tema da Gestão do Patrimônio Cultural: Rio de Janeiro, Iphan, 2009.

RODRIGUES, Deise S. et al. Escola de Cantaria de Ouro Preto: Pesquisa, Oficina e Preservação Patrimonial, Belo Horizonte: Anais do 2 Congresso Brasileiro de Extensão Universitária, 2004.

STAVIS, Bruna, Ensaios Laboratoriais, São Paulo, Editora PINI, 2011.
VARES, Sidnei F de: O Papel da Universidade na Sociedade Brasileira: educação e pesquisa no ensino superior: São Paulo, 2013.

Contribuição ao

1‥ Simpósio Brasileiro de Caracterização e Conservação da Pedra 14 a 16 de dezembro de 2016, Congonhas - MG

Nota:

É de responsabilidade da comissão editorial do Simpósio a revisão gramatical, ortográfica, de citações e referências bibliográficas.

As normas de submissão podem se diferenciar das desta revista. 